\title{
Modos de narrar, formas de descrever: processos de (trans)crição de um corpo ${ }^{1}$
}

\section{Ways of telling, forms of describing: the processes of (trans)cription of a body}

Thiago Siqueira Venanzoni²

1 Uma primeira versão deste trabalho foi apresentada no I Simpósio de Crítica de Mídia: Como Criticam os que Criticam, realizado em 21 e 22 de setembro de 2017 na Universidade Federal de Santa Catarina (UFSC).

2 Doutorando do Programa de Pós-Graduação em Meios e Processos Audiovisuais (PPGMPA) pela Escola de Comunicações e Artes da Universidade de São Paulo (ECA-USP). Membro do Grupo de Estudos da Linguagem: Práticas Midiáticas (MidiAto). E-mail: thiagovenanzoni@usp.br. 


\section{Resumo}

Este artigo apresenta três análises de obras audiovisuais que se ligam pela temática e por compartilharem formas descritivas que se assemelham: 1) o filme Corpo elétrico (2017), de Marcelo Caetano; 2) o documentário Meu corpo é político (2017), de Alice Riff; e 3) Liberdade de gênero, programa veiculado pelo canal GNT no ano de 2017. O tema que atravessa essas três produções é a questão do corpo trans e periférico em relação ao social habitado por essas personagens. Diante desse emblema contemporâneo, trazem-se ao debate as transcrições desses corpos nas mídias na sua relação com o normativo. Compreende-se nos três objetos que a mediação diante do que se mostra neutro se dá na paridade entre os corpos, ao encaminhar-se apresentações descritivas e narrativas de um corpo em disputa no campo político e de formas de sociabilidade por ele apresentadas.

Palavras-chave

Cultura audiovisual, corpo, alteridade, trans, neutro.

\section{Abstract}

This article presents the analysis of three different audiovisual works that are thematically related and that share similar descriptive strategies: 1) the movie Body Electric (2017) by Marcelo Caetano; 2) the documentary My body is political (2017) by Alice Riff; and Liberdade de Gênero, a television show aired during 2017 on the Brazilian network GNT. The theme that crosses all three productions is the presence of a trans and peripheral body related to the social environment where these characters live. Considering this contemporary emblem, we debate the transcription of these bodies in media in their relation with the norm. From the three works, we comprehend that the mediation regarding what is shown as neutral is in the equivalence between the bodies, by describing and narrating bodies in dispute in the political field and the forms of sociability they bring.

\section{Keywords}

Audiovisual culture, body, otherness, trans, neutral. 


\section{O que é o neutro?}

Em um dos seus últimos cursos ministrados no Collège de France, durante alguns meses de 1978, Roland Barthes, mais próximo dos estudos literários, se intriga com uma antidenominação presente em diversas figuras textuais. Elencou ao todo 23 imagens, como chamamos: textos ou figuras nomeadas por ele como traços, que seriam materialidades ou encarnações do que caracterizou como neutro. Em uma das primeiras atualizações do seu conceito, Barthes afasta qualquer semelhança entre o neutro e a indiferença, ou seja, não se trata de algo apagado, mas cintilante e potente, que remete a "estados intensos, fortes, inauditos" (BARTHES, 2003, p. 19). Em outro caso, localiza o neutro como elemento que burla o paradigma e refaz as instâncias binárias colocadas antes de sua aparição ao tirá-las do seu lugar fixo. Em condição semântica, a título de exemplo, essas instâncias seriam o preto e o branco ou o homem e a mulher. Para o autor, o que cria oposição está dentro de um paradigma na linguagem, ou, como ele mesmo refere, "o paradigma é o móbil do sentido; onde há sentido, há paradigma, e onde há paradigma (oposição), há sentido" (BARTHES, 2003, p. 17). O neutro seria, nessa postulação, o que não traz em si um sentido, tendo como função linguística uma desconstrução do paradigma de oposição e, de algum modo, a tradução de uma não inscrição.

$\mathrm{Na}$ argumentação do neutro, Roland Barthes apresenta diversos exemplos do que seria essa figura em campos discursivos variados na classificação linguística. No caso em questão, destaca-se um dos pontos por ele apontado: "Gramática: gênero nem masculino nem feminino, e verbos (latim) nem ativos nem passivos, ou ação sem objeto" (BARTHES, 2003, p. 17). Ou seja, seria algo que não está em lugar definido na linguagem; "aquilo que não está" poderia ser uma definição que se aproxima do que propõe em relação ao conceito. Entretanto, apesar de tratar de funções da linguagem por meio da literatura, alerta-nos o autor que não se trata de uma disciplina do neutro. Ao contrário, a intenção é de uma busca pela categoria "que permeia a língua, o discurso, o gesto, o ato, o corpo, etc." (BARTHES, 2003, p. 19). O filósofo se mostra preocupado, assim, podemos supor, 
com uma fenomenologia do neutro, ou seja, com o modo como essas figuras traduzem e mediam percepções, ações e estéticas presentes no cotidiano.

Há todo um movimento de Barthes, ao longo desse curso, de decifrar o que nomeou como desejo de neutro na literatura ocidental ou, com pequenas variações, diríamos, certa busca por dar destino ao que não tem um sentido fixo. Não nos parece a conversa a ser estabelecida neste momento - ainda que sejam de grande relevância a hipótese e metodologia apresentadas pelo linguista -, e sim ressaltar a questão de estarmos a todo instante dizendo e sendo ditos na linguagem. Ao se referir às figuras do neutro, Barthes coloca também que não há inscrição sem mediação, ou seja, tudo passa por plataformas maiores, discursivas, e a linguagem se define como espaço de enunciações. Parece, em alguns momentos, banal reafirmar tal posição, porém, por vezes, há na crítica social uma crença no legítimo e no autêntico que se esquece dos processos culturais e discursivos ativos na cena social como o véu de ações dos sujeitos.

Trazendo o debate para o campo político, sem nunca perder de vista a linguagem, vasta literatura se coloca mais presente em pesquisas acadêmicas da atualidade, sobretudo a partir dos trabalhos da filósofa norte-americana Judith Butler (2003, 2011), que marca um campo transdisciplinar atuante na antropologia, sociologia, comunicação, filosofia, linguística, literatura etc. Esse campo denominouse estudos de gênero e há uma busca candente a ele em todo o mundo ocidental. No Brasil, o interesse por esse modo de análise e pesquisa também ganhou espaço na academia e em outros meios, o que mobiliza, em contrariedade a ele, sujeitos reativos que se mostram ausentados de um poder idealizado em decorrência da aparição do neutro em diversos registros e escritos e que passam a tratá-lo como ideologia em vez de literatura, imagem, ciência etc. Essa reação conservadora do paradigma localiza não apenas um afeto no campo político como também nos faz compreender a precariedade desses corpos em relação à sua enunciação no social ou no âmbito da linguagem. Está reservado, dessa forma, um local à margem dado a eles na atuação política, tanto por certo modo de torná-los novamente ausentes como por reificá-los e fetichizá-los em processos de consumo no neoliberalismo - 
porém, há uma terceira margem do rio possível, que nos três objetos audiovisuais analisados aqui se caracteriza, como veremos, em dois aspectos: a precariedade do corpo trans e a periferia da cidade de São Paulo.

Retomando o pensamento de Butler, poderíamos localizar o neutro de Barthes também como propriedade da linguagem, visto por ela como o campo de enunciações e atuações performativas nas quais sua condição, de algum modo, desvelaria a antinaturalidade das identidades encaradas socialmente como naturais, do homem e da mulher. Porém, segundo o que nos coloca Sara Salih (2012, p. 66), crer que a identidade de gênero é uma sequência de atos da linguagem não é o mesmo que dizer que há uma autonomia do sujeito ou performer,

ela [Butler] esboça aqui uma distinção entre performance (que presume a existência de um sujeito) e performatividade (que não o faz). Isso não significa que não há sujeito, mas que o sujeito não está onde exatamente esperaríamos encontrá-lo - isto é, "atrás" ou "antes" de seus feitos.

Essa importante distinção que Salih traz ao comentar a obra de Butler nos ajuda a compreender a herança fenomenológica e hegeliana da filósofa, que não altera seu pensamento sobre os conceitos de desejo e alteridade advindos dessa filiação. Ou seja, falar em performatividade é também apostar em uma dimensão do sujeito que realiza dialeticamente seu espaço de relação, o social, e é simultaneamente instaurado por ele em atos discursivos. Os dois movimentos do sujeito que habita um corpo não apreendido socialmente, neutro, são válidos nessa percepção: um lugar que necessita de outros discursos para ser instaurado ao mesmo tempo em que sua aparição ou presença realiza uma mudança no paradigma das falas e ações dos sujeitos. Isso nos faz refletir sobre o aspecto da fala de um "si" que não apenas relata sua experiência como indivíduo, mas também uma experiência da individuação, em suas mais variadas condições de performance e enunciação. No caso dos exemplos referidos neste artigo, nota-se a presença do relato pessoal das várias personagens sobre suas vidas, porém, há uma dimensão descritiva das imagens e das encenações que refundam o lugar desse corpo em perspectiva social. Como já dito, seu lugar é à margem, que 
não o reifica e nem o conserva em falas reativas, e procura um entremeio de posicionamento e convívio ao que chamamos de figuras de alteridade em relação a esse corpo marginal.

Faz sentido, portanto, pensar que esse lugar do corpo transcrito em narrativas audiovisuais é um exercício que corresponde à linguagem e aos modos de percebê-lo socialmente, ou seja, em sociabilidades que caminham para a busca de reconhecimento desses corpos.

\section{Figuras de alteridade}

Uma condição que se impõe, portanto, aos debates em torno do reconhecimento e das críticas social e da cultura ao se tratar das mídias é o processo de transcrição desse corpo precário diante do paradigma que se coloca aos observadores ou espectadores. O desafio é não constituir, na crítica, uma tautologia da representação, que crê numa transformação social ou na sociabilidade pactuada a partir de uma visibilização do corpo trans, não binário, em espaços midiáticos sem questionar, propriamente, os modos e a forma política dessa visibilidade. Se pensarmos em certos conceitos da linguística, caso evidente no trabalho de Louis Hjelmslev, a tautologia seria um tratamento do plano do conteúdo, ou seja, do significado, que não levaria em conta o plano de expressão, ou significante. Ao nosso modo, pensamos que o conteúdo deve ser relacionado ao significante - à cadeia que o coloca em sentido - ou à narrativa que o comporta. Em medida simétrica, o plano do significado também não parece estar relacionado à questão trazida por Barthes sobre a figura do neutro e sua discussão a respeito da destituição paradigmática dos binarismos. Seu interesse, assim como o que tentaremos apresentar neste momento, é compreender o que poderia ser apreendido como esse rasgo em relação ao que está estabelecido, naturalizado e culturalmente pactuado.

Optamos por trazer três obras que nos colocam diante de tematizações semelhantes dentro de processos culturais. Tratam-se de três gêneros audiovisuais que se distinguem - o cinema ficcional, o documentário e a série televisiva -, porém, nossa intenção é inverter certo pragmatismo do modelo analítico apostando 
no discurso audiovisual que se mostra nas obras em causa. Reconhece-se, assim, nessas produções, o documentário Meu corpo é político, o filme Corpo elétrico e o programa de televisão Liberdade de gênero, que apresentam semelhanças narrativas e na traduzibilidade desse corpo em disputa, algo que tentaremos demonstrar no processo de descrição dessas obras.

Além desses fatores, esses trabalhos entram em uma dinâmica das imagens referenciais no contemporâneo que não se colocam mais no binômio documental ou ficcional, mas fazem parte de uma cultura audiovisual e midiática que escapa, digamos, aos formatos que a originam. Evidente que há diferenças em relação aos gêneros e formatos de cada uma das obras, porém, não seria esse nosso maior interesse no momento, e sim nos dedicarmos à compreensão de como essas imagens são apresentadas em objetos da cultura audiovisual e como respondem a certas demandas de representação e performatização do corpo e outras questões em debate. Poderíamos dizer, a exemplo do que faz, de forma exímia, Barthes em relação à cultura letrada de um determinado período histórico em seu curso. Nossa intenção, porém, é bem mais modesta e pretende se expandir em discussões para além das características expostas por este texto.

O documentário Meu corpo é político (2017), dirigido por Alice Riff, colocase distante do modelo predominante de documentário quando evita, de forma deliberada, as entrevistas. A câmera se coloca em fluxo para mostrar a vida das personagens que encenam o seu cotidiano na escola, no trabalho, em casa etc. Essa estratégia discursiva, de algum modo, reconhece a voz das personagens como algo a ser ouvido mais do que questionado ou conduzido por uma narração em off. As personagens também foram escolhidas para observar a vida em dois sentidos fundantes ao se trabalhar questões éticas e morais, sobretudo na realidade brasileira: as questões de gênero e classe ${ }^{3}$. em movimentos sociais diversos por estarem em lugares distintos, sendo que a primeira está mais no plano ético das relações, das paixões e dos afetos, e a segunda no plano moral, das leis e dos direitos sociais. De algum modo, o filme ocupa-se dessa preocupação ao aproximar as duas questões a partir das personagens. Cf. Honneth e Fraser (2003). 
São quatro personagens apresentadas, Fernando Ribeiro, Giu Nonato, Paula Beatriz e Linn da Quebrada; quatro corpos trans em disputa cotidiana nos espaços de conflitos em relação ao neutro, ao não binário que elas encarnam na vida e na obra audiovisual. As primeiras personagens, Fernando Ribeiro e Giu Nonato, namoram. Uma é homem trans e a outra, mulher trans, ambas vivendo na periferia de São Paulo. Fernando trabalha como atendente de telemarketing de uma empresa de aviação comercial; sua busca é o reconhecimento do nome social e pagar a dívida ocasionada pelas intervenções cirúrgicas da mudança de sexo, realizada com recursos particulares e não pelo Sistema Único de Saúde (SUS). Diz Fernando em conversa com a equipe de defensoria pública que Ihe atende: "ganho um salário mínimo e a dívida é descontada em folha. Sinto que o Estado me deve".

Outra personagem é Paula Beatriz, diretora de escola pública na periferia paulistana. Sua história já foi tematizada em outros espaços midiáticos por ser a primeira diretora trans de uma escola no estado de São Paulo; comenta sua trajetória em encontros com grupos de militância no bairro em que reside. Linn da Quebrada, a quarta personagem, se apresenta em shows em diversos espaços da cidade, mora em Sapopemba, bairro distante do centro paulistano, em um conjunto residencial da Companhia de Desenvolvimento Habitacional e Urbano de São Paulo (CDHU) e trabalha em favor de sua carreira musical.

Nessas narrativas trazidas pelo documentário compreende-se, num sentido bastante expandido, a enunciação fílmica que traz a necessidade da ação pública institucional coexistindo com esses corpos trans, seja ao apontar a ausência do financiamento público para as intervenções cirúrgicas ou a dificuldade de mudança do nome social e, na mesma relação, a atuação da defensoria pública nesses temas pouco reconhecidos. No caso de Paula Beatriz, o fato de ser admitida como diretora de um colégio público, um dos poucos lugares que aceitariam tê-la nessa condição hierárquica, é fruto de uma posição alcançada por concurso público. Já Linn da Quebrada oferece aulas de teatro, performance e leitura de textos para jovens no centro educacional unificado (CEU) de Sapopemba, instituição pública da cidade, além de morar em complexo habitacional derivado de investimentos 
públicos. Há, portanto, nessa introdução às histórias, marcas tanto da dimensão ética do reconhecimento quanto da dimensão moral da redistribuição, que se ocupa em ofertar ou retirar possibilidades existenciais aos corpos periféricos, sobretudo quando o espaço em disputa é a cidade de São Paulo, com marcas bastante evidentes também da desigualdade social do país.
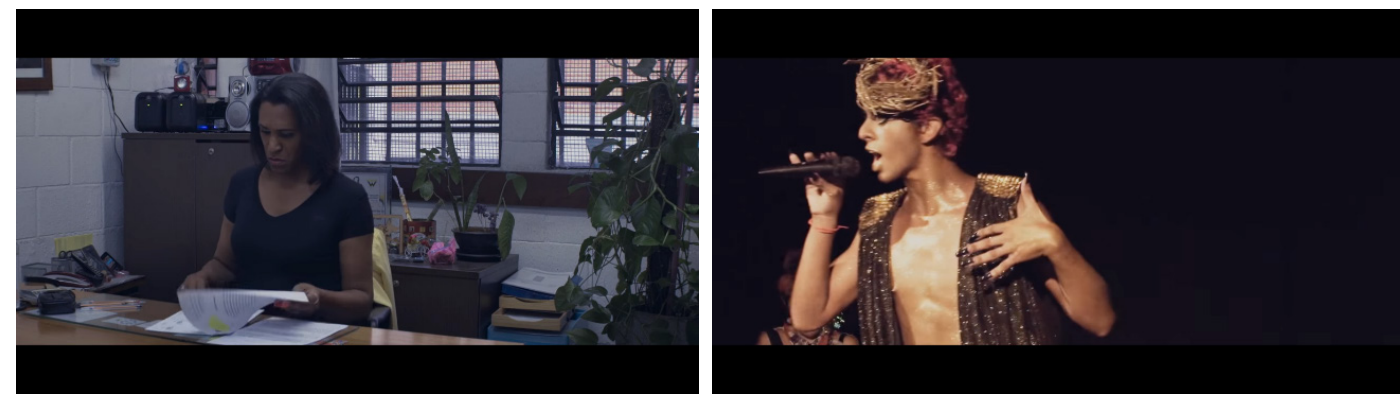

Figuras 1 e 2: Paula Beatriz e Linn da Quebrada

Fonte: Meu corpo é político (2017)

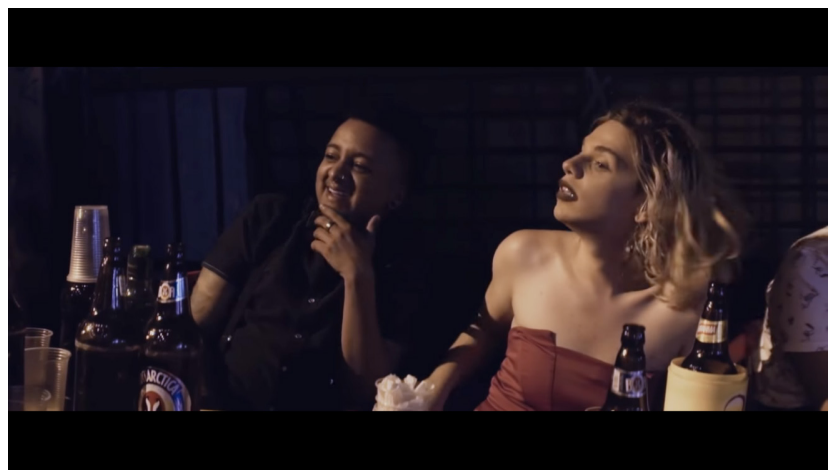

Figura 3: Fernando Ribeiro e Giu Nonato

Fonte: Meu corpo é político (2017)

O espaço de atuação é a periferia de São Paulo e todos os elementos que incorporam a complexidade social desse território urbano. Consideramos, por outro lado, que a complexidade permite maiores brechas do que uma unicidade nos entendimentos estético e relacional da vida em sociedade. Como exemplo, é bastante comum compreender a convivência entre os corpos trans, duplamente periféricos, e figuras religiosas no espaço privado da casa e da família, em que se ausenta a figura masculina do pai e há compreensão mútua dos sujeitos em 
relação a suas existências no social - como, no caso proposto, da mãe e a filha trans. São outros modos de estar que, por vezes, não seriam compreendidos em certos espaços sociais estáveis, nos quais a idealização da família e também os processos de fé costumam ser mais reativos ao corpo trans.

Na complexidade do documentário também não se apresentam, na rotina das quatro personagens, situações de conflito permanente; ao contrário, percebe-se que a narrativa em fluxo se abstém de juízo prévio e localiza eventos absolutamente banais, mas que na obra se mostram potentes em função da naturalidade com que essas pessoas buscam as sociabilidades e vivências com o comum, com a intenção de encontrar um comum que insira esses corpos. Assim, o que responde à demanda do Outro discursivizado na narrativa, trans e não binário, é um Mesmo que lhe coloca experiências de sociabilidade e a construção de diferentes modos de vida. Há, dessa forma, uma troca valiosa estabelecida pelas figuras de alteridade da narrativa, que não procura excluir o Outro, mas apresentá-lo, ressocializá-lo.

De outra maneira, o conflito desses corpos não binários da periferia urbana, na narrativa, se apresenta mais em experiência externas, não privadas - ou seja, nas instâncias burocráticas requeridas para a mudança do nome social, na ida à ginecologista que não compreende o corpo masculino com vagina, como relatado por Fernando, ou nas distâncias percorridas para chegar, a partir do transporte público, de um ponto ao outro da cidade, algo que chega a durar duas ou três horas. Essa cotidianidade, também referida na narrativa, se mostra como um entrave no reconhecimento dessas noções de si que as personagens relatam, um corte nos afetos possíveis de existência. Dessa maneira, essa obra se assemelha às outras duas que nos dedicaremos a relatar na sequência como demonstração das figuras de alteridade já apresentadas, em dinâmica de conflito e reconhecimento do corpo trans e suas possibilidades no social.

\section{0 íntimo familiar}

O espaço íntimo da casa e da família se coloca como algo bastante frequente nas produções audiovisuais que buscam traduzir as questões que envolvem 
a escolha de gênero. Os relatos dessas vozes nas mídias tematizam tanto o reconhecimento familiar, em narrativas de sucesso, como o não reconhecimento da família, em narrativas trágicas, sendo ambas bastante simplificadoras nessa apreciação e apostando, nesse momento, em uma ilustração ou caracterização dessas recorrências. Possibilitando à crítica um maior grau de complexidade, a família parece conduzir um entendimento da linguagem como prática social de corpos não apreendidos em um mundo idealizado e projetado externamente. Dito de outra forma, o primado da família e do íntimo em vários relatos e narrativas tem que se associar a uma construção de sujeito em seu discurso para que haja validação daquilo que se coloca em conflito no campo relacional. Isso nos faz intuir que a família é, em si, um lugar no qual se demonstra possibilidades de existências desses corpos, mesmo em situações mais deletérias, como a ausência do reconhecimento familiar ou as violências domésticas contra ele.

Outro modo de pensar sobre o tema pode ser encontrado nas figuras de alteridade que Hegel nos apresenta em sua tese da dialética relacional. Não convém em nossa descrição dedicar tempo demasiado ao que nos apresenta Hegel, mas compreender que, entre as figuras por ele pensadas, a que importa à linguagem poderia ser melhor dedicada às constatações e absolvições em torno do reconhecimento familiar (as outras duas figuras, trabalho e desejo, serão tópicos no próximo item deste artigo). Caminhando um pouco mais sobre essa trilha, podemos compreender que o campo da linguagem e as primeiras experiências dos sujeitos, que se dão no espaço familiar e íntimo, são também os locais nos quais são inscritas as primeiras marcas, conscientes e inconscientes, de identificação e negação de identidades ou não identidades antes colocadas.

Entretanto, determinadas leituras da tese hegeliana, como a apresentada por Vladimir Safatle (2012), creem ser simplificador imaginar que toda a experiência do sujeito se centraliza no conceito relacional, pois poderia levar a pensar que toda relação subjetiva é um construto de relações intersubjetivas que antecedem e sucedem os sujeitos e, mais ainda, de que tudo se concentra nos indivíduos. Há uma demanda coletiva na tese hegeliana e isso não deve ser perdido; uma 
diferente consciência-de-si que não é cerrada pela relação com outro indivíduo e que se imponha, dessa maneira, em outros lugares nos quais o indivíduo não faz necessariamente presença. De outra forma, como explicar e defender o reconhecimento de um corpo inacessível na linguagem em sua complexidade (por exemplo, o corpo trans)? E como separar certas experiências apreendidas no espaço social mediado pela cultura midiática de um contexto maior que coloca à margem o corpo trans? Essas perguntas, que aqui cumprem função retórica, nos ajudam a intuir que a construção narrativa desses corpos, na forma como essas obras audiovisuais buscam descrevê-los e transcrevê-los, não se restringe ao íntimo das vidas apresentadas apenas, mas compreendem uma condição social que amplifica experiências e instaura discursos. Nessa condição, compreendemos tanto o plano ético do reconhecimento e das lutas identitárias quanto o plano moral de práticas culturais, políticas públicas, direitos em disputa e outras circunstâncias que implicam esse corpo na cena social.

O espaço íntimo e relacional da família e seu processo de reconhecimento de um corpo incompleto (inaudito) na linguagem são importantes se trabalhados nessas duas dimensões da compreensão do corpo trans no âmbito da cultura. Não de outro modo, parecem andar em companhia ao se tratar do tema e isso se esboça nas narrativas, inclusive essas aqui utilizadas. Linn da Quebrada, personagem do documentário Meu corpo é político, é também o tema do episódio três da segunda temporada de Liberdade de gênero (2017), série veiculada pelo canal pago GNT. A obra é dirigida pelo cineasta João Jardim e traz histórias distintas que compreendem a escolha íntima do gênero na vida social de personagens trazidas ao seu relato cotidiano. Adotando contexto semelhante ao da produção anteriormente trabalhada (o filme de Alice Riff), a série prefere oferecer à personagem o encaminhamento descritivo da sua vida; porém, ao contrário de Meu corpo é político, há uma centralidade, ao menos nesse episódio, da fala testemunhal da personagem e uma montagem mais presente, com cortes que apresentam o ambiente da casa, a presença da mãe na vida de Linn, entre outros momentos de intimidade. No filme de Riff, o 
testemunhal aparece nas situações cotidianas encenadas ou nas imagens que dimensionam o estado social desses corpos.

Nesses relatos, Linn questiona a relação entre religião e gênero, a não aceitação da mãe e o relato desta - que, após algum tempo, passou a aceitar quem "sempre achou linda": a filha. Essa sequência, que ocorre de forma não linear na narrativa, apresenta as dimensões antes trabalhadas da compreensão e do reconhecimento familiar como pilares na descrição do corpo trans projetado socialmente. Como já mencionado, parecer haver necessidade, no campo midiático, do âmbito de um Mesmo que faça luz ao Outro obscurecido que destina uma aceitação. O risco dessa mediação é restringir as potencialidades desse corpo, compreendê-lo em apenas alguns lugares e não em outros possíveis, ou seja, torná-lo uma experiência não dialética e positivar modelos em torno de um corpo subalterno que não consegue recusar os estigmas impostos, ainda que deseje outros modos de aparição.

Não identificamos que seja esse o caso da transcrição realizada pelo programa Liberdade de gênero, ao menos nesse episódio em questão. A apresentação dos emblemas de Linn evidencia os conflitos, as condições sociais desses corpos marginalizados - dela e da mãe -, a compreensão de outra forma de sociabilidade reservada ao íntimo, mas que aponta para outras mediações, e o convívio possível entre diferenças, quando prevê discursos reativos e conservadores. Quando Linn da Quebrada relata sua experiência enquanto testemunha de Jeová em um corpo trans, ainda que compreenda a inadequação entre esses dois modos de ver o mundo, não há ali incoerência. Nem dela, que abandonou a religião, nem da mãe, que continua a frequentar a igreja e entende as potencialidades da filha e do seu corpo. O episódio desfaz, a quem optar por encarar desse modo, certo tipo de polarização que se construiu em torno das lutas por reconhecimento, restritas a algumas classes sociais no Brasil, e as igrejas neopentecostais que constituem maioria nas periferias brasileiras. Há, supomos pelo episódio, uma dimensão do popular que compreende os neopentecostais e as variabilidades do corpo trans sem localizar nisso algo incoerente, dissonante, mas parte de um 
mesmo espaço social e de classe. Resume-se, enfim, que o episódio nos coloca formas possíveis de estar socialmente, de reconhecimento no âmbito do gênero e construção do coletivo a partir de um íntimo que se inscreve na linguagem como algo vivo, existente.
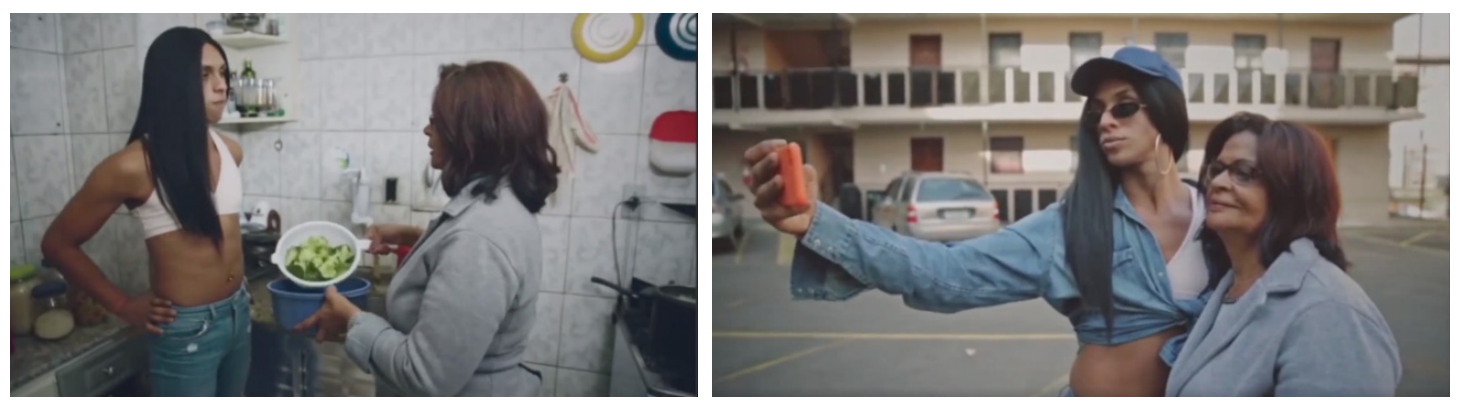

Figuras 4 e 5: Linn e sua mãe na cozinha e na área externa no prédio Fonte: Liberdade de gênero (2017)

Na primeira obra audiovisual analisada, a de Alice Riff, nota-se a presença desses corpos em disputa no campo social, muitas vezes hostil a eles, e na sua atuação política, no trabalho e em momentos de encontros com diversas pessoas em espaços públicos. Essas funções são apresentadas em ações encenadas pelas personagens em seu cotidiano. No segundo objeto trazido à análise, a série documental dirigida por João Jardim, nota-se o depoimento testemunhal como importante na condução narrativa, apostando nos relatos dele para dimensionar o espaço social dessas personagens. No caso do episódio trazido para o artigo, a presença familiar e do íntimo na vida de Linn da Quebrada, artista e personagem do capítulo, reafirma uma enunciação recorrente na apreensão do corpo trans: o reconhecimento familiar. Nota-se, ainda, que essa descrição da série sobre o testemunho de Linn traz consigo uma complexidade que se refere também ao externo e à não apreensão desse corpo em outros espaços, além de propor formas possíveis de sociabilidade entre o mundo externo e o íntimo referido na narrativa. A terceira obra apresenta, por sua vez, as figuras de alteridade que não convergem num mesmo lugar. Há, assim, um conflito transcrito entre as potências do corpo trans, periférico, seus desejos e o mundo do trabalho. 


\section{O trabalho e o desejo}

O filme de Marcelo Caetano, Corpo elétrico (2017), descreve o cotidiano de uma fábrica têxtil no bairro do Bom Retiro, em São Paulo, e a presença de corpos trans e periféricos dentro dessa comunidade industrial, em uma relação que se coloca entre dois campos da alteridade: o trabalho e o desejo. Esses campos são presenciados no filme como opostos, não conciliáveis, em que o trabalho precarizado não permite a vazão do desejo. Para usar o título do filme, o corpo elétrico, potente, candente não é compreendido dentro do trabalho a que esses corpos são submetidos para seu reconhecimento nas práticas sociais, como sujeitos, e sobrevivência no mundo neoliberal.

A primeira imagem que surge é de corpos não totalmente definidos, entrelaçados um ao outro, e a personagem Elias, que relata um encontro com o mar. O sargaço trazido como metáfora em seu relato de sonho é o que marca a presença do desejo corpóreo de permanecer em mar aberto - sem destino, em breu absoluto -, algo que não se configura como um futuro projetado ou o oposto, que propõe o mundo do trabalho contemporâneo e suas regras de ascendência social, limite do corpo e hierarquia dentro da companhia que o emprega.

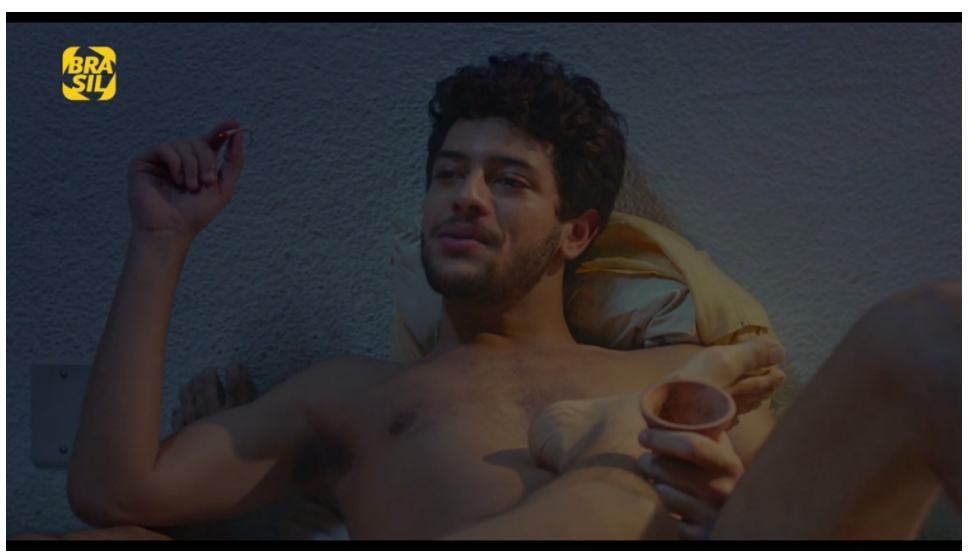

Figura 6: Elias relatando a sua experiência onírica no mar Fonte: Corpo elétrico (2017)

A personagem Elias é como um elo possível entre esses mundos irreconciliáveis, um corpo aceito pelo mundo do trabalho, reconhecido pelos 
empregadores, ainda que dentro de uma ética corporativa, e que transita entre os outros sujeitos que se encontram no mesmo espaço. Por essa razão, a narrativa percorre sua percepção sobre esses mundos, sua presença em encontros de empregados e empregadas da confecção, o churrasco, o futebol de domingo e o show performático das drags que moram com um dos empregados, Wellington.

Esse percurso narrativo apresentado por Elias aos espectadores revela a incompatibilidade desses mundos, que se encontram por acaso social, descrito no emprego, e uma motivação que não está ligada ao desejo de experiência dos sujeitos, mas antes pela instauração desses corpos marginalizados na linguagem e na cultura. A incompatibilidade reside justamente em não haver o reconhecimento das razões desses corpos, de suas vontades e desejos, e localizálos sempre dentro de determinados estigmas de subalternidade. Os corpos do negro, do refugiado, da mulher negra e de trans se encontram na confecção para dali compreenderem seus lugares de imposição e fazerem sua recusa a eles, mesmo que permaneçam ocupados dos estigmas por uma questão social dada. Elias não é parte desse atravessamento dos corpos periféricos, ainda que se identifique com eles em vários pontos e traduza em práxis um reconhecimento de seus desejos. Ele seria na narrativa uma espécie de esteio moral para uma sociabilidade idealizada, em que haja um lugar de encontro entre o mundo do trabalho e o mundo do desejo.
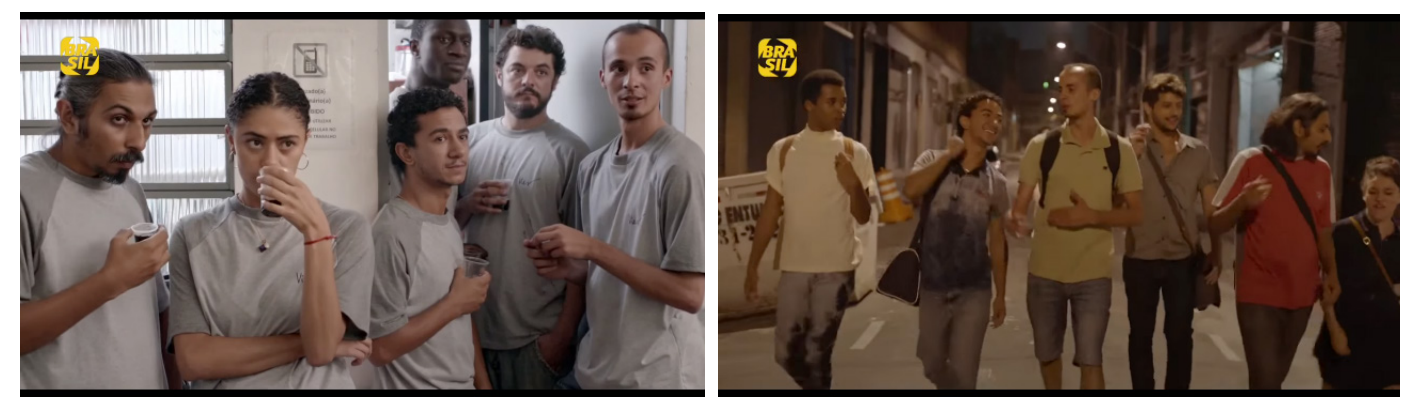

Figuras 7 e 8: Cena em que os empregados são informados pelo patrão da hora extra que precisam fazer e cena posterior, em que saem do trabalho para um bar Fonte: Corpo elétrico (2017) 
Há uma diferença nas imagens que se refere aos distintos pactos sociais estabelecidos entre os sujeitos em cena e as duas figuras de alteridade, o trabalho e o desejo. A alteridade é importante para mediar esses corpos na percepção social, localizá-los em formas múltiplas na linguagem, algo que a obra audiovisual traduz no interior de sua narrativa como propriedade discursiva das imagens, sobretudo. A todo momento essas diferenças são trazidas em cenas que são sobrepostas na montagem, a fim de marcar a oposição dos espaços de experiência dos sujeitos.
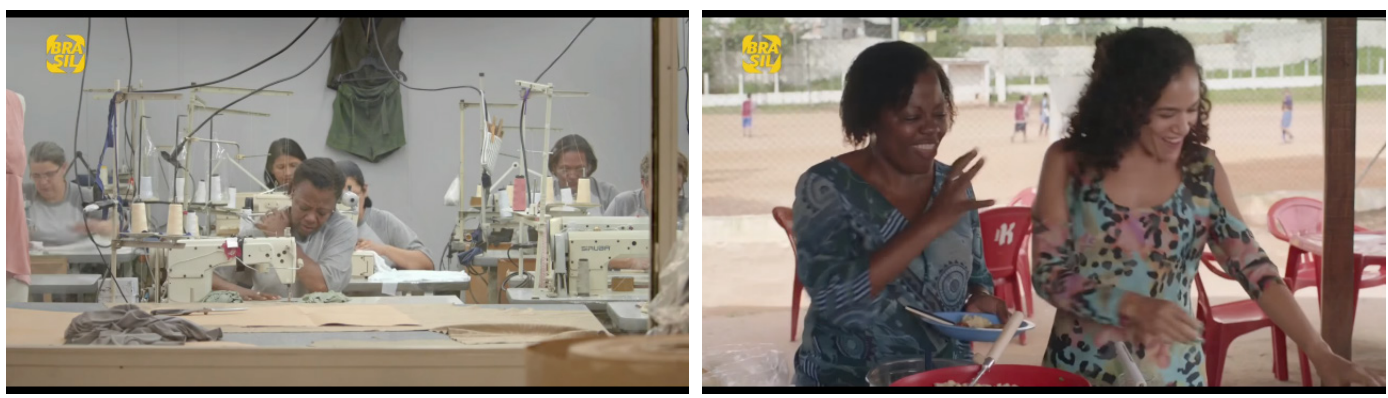

Figuras 9 e 10: Maria, empregada da confecção, com dores no ombro provocadas pelo movimento repetitivo da máquina de costura e o receio em ser demitida ou afastada do trabalho e, depois, animada no churrasco com os outros empregados Fonte: Corpo elétrico (2017)

O título do filme transcreve o que seriam as inscrições nos corpos, a ausência de intensidade no mundo do trabalho, as dores, o desconforto e o corpo do desejo, descrito em outro lugar. Nota-se também, em igual medida, como as figuras da alteridade atuam em relação aos corpos invisibilizados em suas experiências no social ao possibilitar novos olhares a eles, outros enunciados possíveis e novas narrativas que emergem a partir das transcrições dos corpos em cena. Há pouco tratou-se de pensar as duas relações com o corpo e a experiência na personagem Maria; porém, isso se torna mais evidente na condição do corpo não apreendido de Wellington, que decide sair do espaço que lhe prende e dar vazão ao seu desejo de performar um outro, como drag, ao anunciar a Elias sua saída da confecção do Bom Retiro para viver de apresentações na noite de São Paulo. 

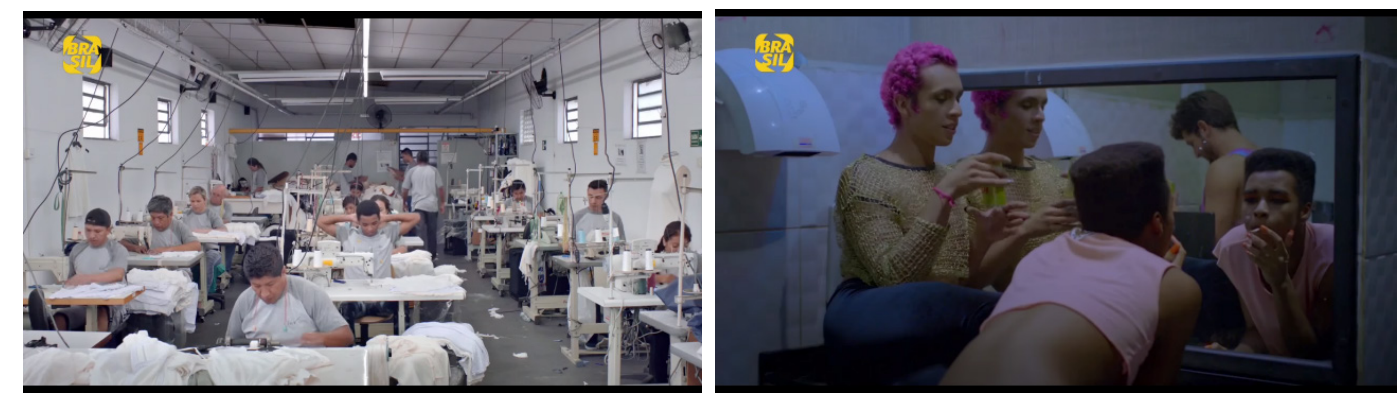

Figuras 11 e 12: Wellington, no centro do plano, se espreguiçando com dores no corpo pela posição na máquina de costura e, em seguida, na noite de São Paulo Fonte: Corpo elétrico (2017)

Essa personagem faz criar um imaginário em relação à precarização do corpo trans num mundo que não permite sua existência enquanto tal. Enunciase, portanto, a incompatibilidade de uma possibilidade de neutro dentro de um espaço social mediado em que o paradigma é a única permissão, com as oposições corpo negro/corpo branco, mulher/homem e brasileiro/refugiado. Essas diferenças marcam o lugar de cada sujeito na confecção enquanto a mistura se dá no campo do desejo, fora do mundo do trabalho, em que o reconhecimento não se ocupa permanentemente das regras binárias. $\mathrm{O}$ trabalho dimensiona as possibilidades do que está fora dessa figura de alteridade, ou seja, sua ausência é o que se traduz como potência na descrição desses corpos subalternos em cena.

\section{Alinhavando (trans)crições}

Conclui-se este artigo com a certeza de que outras coisas poderiam ser ditas das obras elencadas para análise, dada a complexidade de suas narrativas e o jogo abertamente realizado por elas entre fora e dentro, ou seja, uma recorrência em relação ao que está na obra e ao que ele responde ao mundo, inquietações e demandas da vida cotidiana. Uma espécie de associação entre arte e vida no lugar que as obras audiovisuais podem alcançar: uma estética mediadora das contradições sociais e das funções da linguagem presentes em nossas sociabilidades. 
A partir dessa premissa - como narrar e descrever esses corpos -, pensou-se na associação entre as várias formas de dizer que essas obras, todas realizadas no mesmo ano, se propuseram como discursos. Nelas encontraramse, assim, recorrências, que se ligaram a outras inquietações deste texto em torno dos conceitos de reconhecimento e construção de identidades, em sua dimensão ética (mais presente nos dias atuais) e em seu plano moral, ligado às práticas culturais, aos modelos de justiça social, às leis e às políticas públicas. Não parece acaso que ao falar desses corpos as obras audiovisuais optem por pensar em corpos trans e periféricos, existentes na cidade de São Paulo, em sua dimensão política e social, ou seja, à margem em vários sentidos da vida. Nosso interesse, portanto, parecia dado a partir do que essas produções nos apresentavam e caminhava-se por aí a trilha descritiva e analítica dos objetos empíricos do artigo.

Os conceitos trazidos - em Roland Barthes, do neutro, e em Judith Butler, da perfomatividade -, nos ajudam a compreender também os processos de transcrições e descrições dos corpos inauditos, localizando-os como propriedades da linguagem, de práticas discursivas e culturais, na busca pelo reconhecimento no modo de enunciar esses corpos em suas multiplicidades e formas. Foram suficientes para se pensar que não há possibilidade de idealizações ao considerá-los no campo da linguagem e balizá-los com outros espaços socialmente legitimados, nomeados no texto como figuras de alteridade, formas já apreendidas no campo social que mediam os corpos trazidos ao debate.

A condição analítica que coube a este artigo se assemelha à poesia de Waly Salomão (2014, p. 293-294), "Sargaços", em que o poeta diz, de forma bastante adequada à cena inicial de Corpo elétrico e à fala de Elias: "Mar de sargaços// Nadar, nadar, nadar, e inventar a viagem, o mapa,/ o astrolábio de sete faces/ O zumbido dos ventos em redemoinho, o leme, as velas as cordas,/ Os ferros, o júbilo, o luto". Em outra sequência, mais ao fim do poema, diz: "Criar é desacostumar do fado fixo/ E ser arbitrário./ Sendo os remos imateriais.// (Remos figurados no ar pelo círculo das palavras.)". 
O processo de construção de um corpo não inscrito passa por descrição e tradução, uma propriedade de construção e escrita presente tanto nas obras audiovisuais quanto no exercício crítico que este artigo colocou como proposta.

\section{Referências}

BARTHES, R. O neutro. São Paulo: Martins Fontes, 2003.

BUTLER, J. Problemas de gênero: feminismos e subversão da identidade. São Paulo: Civilização Brasileira, 2003.

Bodies that matter: on the discursive limits of sex. New York; London: Routledge, 2011.

CORPO elétrico. Direção: Marcelo Caetano. Produção de Beto Tibiriçá e Marcelo Caetano. São Paulo: Vitrine Filmes, 2017. Projeção digital (90 minutos).

HONNETH, A; FRASER, N. Redistribution or recognition?: a political-philosophical exchange. New York: Verso, 2003.

LIBERDADE de gênero. Episódio 4, temporada 2. Direção: João Jardim. Rio de Janeiro: Globosat; GNT, 2017. TV (30 minutos).

MEU corpo é político. Direção: Alice Riff. Produção de Studio Riff e Paideia Filmes. São Paulo: EBC Brasil; Vitrine Filmes, 2017. Projeção digital (74 minutos).

SAFATLE, V. Grande hotel abismo: por uma reconstrução da teoria do reconhecimento. São Paulo: Martins Fontes, 2012. 
SALIH, S. Judith Butler e a teoria queer. Belo Horizonte: Autêntica, 2012.

SALOMÃO, W. Sargaços. In: Poesia total. São Paulo: Companhia das Letras, 2014. p. 293-294.

submetido em: 05 abr. 2018 | aprovado em: 08 maio 2018 